\title{
Understanding the Lifestyle Correlates with Chronic Constipation and Self-Rated Health
}

\author{
Li-Li Chang1, Yu-Chen Lin1, Tsai Chang Lo1, Ming-Chu Chen', Hsien-Wen Kuo ${ }^{2,3^{*}}$ \\ ${ }^{1}$ Public Health Bureau of Miaoli County Government, Miaoli, Taiwan \\ ${ }^{2}$ Institute of Environmental and Occupational Health Sciences, National Yang-Ming University, Taipei, Taiwan \\ ${ }^{3}$ School of Public Health, National Defense Medical Center, Taipei, Taiwan \\ Email: hwkuo@ym.edu.tw
}

Received 26 February 2015; accepted 15 March 2015; published 20 March 2015

Copyright (C) 2015 by authors and Scientific Research Publishing Inc.

This work is licensed under the Creative Commons Attribution International License (CC BY).

http://creativecommons.org/licenses/by/4.0/

(c) (i) Open Access

\begin{abstract}
The objective of this study is to evaluate the healthy and unhealthy behaviors as risk factors for chronic constipation and self-rated health status. Eight hundred tenth students enrolled from a university in Miaoli city, Taiwan. Chronic constipation was assessed using Chinese questionnaire. Information of unhealthy and healthy lifestyles was interviewed by constructed questionnaire. Thirty-six percentage of university students were assessed as chronic constipation. Using multivariate logistic regression adjusted for age, sex, race and BMI, we found chronic constipation significantly correlated with frequency of consumption from snack, fast food, fried food, daily consumption of water, physical activity and junk food used as regular food. Moreover, these unhealthy behaviors significantly correlated with self-rated health status. Students with chronic constipation had poor self-rated health status. It is urgent to create healthy behaviors to reduce the risk for chronic constipation or upgrade self-rated health status in university students.
\end{abstract}

\section{Keywords}

Unhealthy Lifestyles, Chronic Constipation, Self-Rated Health Status, University Students

\section{Introduction}

For issues of digestion, constipation is a common intestinal symptom. In western countries, up to $10 \%$ of children have chronic constipation, but only 3\% of parents seek medical advice [1]. Likewise, constipation is a common problem for Taiwanese school-aged children, especially girls. Employing multi-staged sampling, a nationwide sample of children between 7 and 12 years of age showed that 32.2\% of the sample suffered from consti"Corresponding author.

How to cite this paper: Chang, L.-L., Lin, Y.-C., Lo, T.C., Chen, M.-C. and Kuo, H.-W. (2015) Understanding the Lifestyle Correlates with Chronic Constipation and Self-Rated Health. Food and Nutrition Sciences, 6, 391-398.

http://dx.doi.org/10.4236/fns.2015.64040 
pation. Girls (36.1\%) were more likely to have constipation than boys $\mathbf{2 9 . 2 \% )}$ in this study [2]. Similarly, a community-based survey in Hong Kong investigated the prevalence of constipation in 561 young children aged 3 - 5 years: Almost 30\% of the studied children showed signs of constipation as per the Rome II paediatric criteria [3]. We reviewed 19 papers to determine the range of the prevalence rates of constipation in children and found the prevalence rates to be between $0.7 \%$ and $29.6 \%$ (median $12 \%$ ).

Some of the risk factors of constipation appear in the literature. Common risk factors include being female, increasing in age, low socioeconomic status and low educational level [4]. Other well-known risk factors are diet-related: infrequent consumption of vegetables, fruits, soybean products, and eggs are all associated with childhood constipation [5] [6].

Because many risk factors related to constipation are diet or lifestyle-related, changes in lifestyle can lead to constipation; Taiwan is a suitable place in which to study this effect. Over $90 \%$ of adolescents enter university or college in Taiwan, in part due to the low barrier to college entrance. Because most of students move to other cities or areas, living away from their families, they tend to significantly change their lifestyles, especially in terms of dietary intake or physical activity. Previous studies on healthy lifestyles indicated that the majority of university students are negligent of health-promoting behaviors and engaged in behavioral health risks, such as tobacco use, alcohol and substance abuse, as well as improper diet and physical activities [7] [8]. University students typically enter a dynamic transitional period of new independence from their parents that is characterized by rapid, interrelated changes in body, mind, and social relationships [9]. Inactivity among Taiwan university students is customary [10]. Inadequate health knowledge or limited guidance from their family members can directly lead university students to noncompliance with healthy behaviors, resulting in serious health outcomes.

The literature lacks research on the effects of Taiwan's university students' unhealthy behaviors on constipation during the significant life transition from family to university. Understanding these effects can help health experts target the health beliefs and behaviors that can help students reduce chronic constipation. The objective of this study is to evaluate aspects of healthy and unhealthy lifestyles as risk factors for chronic constipation and determine how they relate to self-rated health status.

\section{Materials and Method}

\subsection{Participants}

We ran a cross-sectional study on 827 university students from different departments. The study protocol was reviewed and approved by institutional review board in Yang-Ming University before any student recruitment and data collection began. 810 students were enrolled in a university located in Miaoli County. The inclusion criteria for the study included being a student of one of the university, being 18 or older, and being free of chronic disease at the time of the study. Each student received an informed consent form receiving an interview via questionnaire.

\subsection{Procedures and Research Instruments}

Each student filled in a structured questionnaire, which included demographic information, healthy behaviors (including the daily intake of at least $1500 \mathrm{~mL}$ of water and regularly eating breakfast), unhealthy behaviors (including eating snacks, fried food and junk food in place of regular food), the symptoms of constipation and self-rated health status. The frequencies of the reported healthy and unhealthy behaviors were measured by a self-report Likert's scale with a five-point response format: never, seldom ( $<1$ day or 1 time/month), occasionally (<1day or 1 time/week), usually ( 2 - 4 days or 2 - 4 times/week) and daily, with the rating scores ranging from 1 to 5 . We performed a pilot test to determine whether this would be appropriate and reliable for our participants.

A proper definition of constipation was important for this study. Constipation generally is defined by the hard nature of the stool, the pain associated with its passage and the failure to pass three stools per week. Our definition of chronic constipation in Chinese came from a Hong Kong study. Six items for constipation were validated with good reproducibility and internal consistency. A cut-off score of $>5$ was determined to discriminate between controls and constipated patients with a sensitivity of $91 \%$ and a specificity of $91 \%$ [11].

\subsection{Statistical Analysis}

We performed statistical analysis using SPSS (SPSS Inc., Chicago, IL, USA). Chi-squared tests compared the 
healthy and unhealthy behaviors for constipated university students and non-constipated students. Multivariate logistic regression, adjusted for age, sex, race and BMI, assessed the healthy and unhealthy behaviors affecting constipation and differences in self-rated health status.

\section{Results}

Table 1 shows the frequency of healthy and unhealthy behaviors in university students and their correlations with chronic constipation. Healthy behaviors, such as the daily intake of at least $1500 \mathrm{~mL}$ of water and regularly

Table 1. Students’ lifestyles correlated with suffering from chronic constipation.

\begin{tabular}{|c|c|c|c|}
\hline & Non-constipated students $(\mathrm{N}=554)$ & Constipated students( $\mathrm{N}=256)$ & $p$ \\
\hline Regular eating breakfast & & & 0.134 \\
\hline None/seldom & $77(17.2)$ & $36(14.1)$ & \\
\hline Regular & $59(13.1)$ & $51(20.0)$ & \\
\hline usual/daily & 313 (69.7) & 168 (65.9) & \\
\hline Eating late-night snack & & & 0.001 \\
\hline None/seldom & $228(51.1)$ & 109 (41.6) & \\
\hline Regular & $153(34.3)$ & $80(31.4)$ & \\
\hline Usual/daily & $65(14.6)$ & $60(7.0)$ & \\
\hline Eating snack & & & $<0.001$ \\
\hline None/seldom & $193(43.1)$ & $62(28.5)$ & \\
\hline Regular & $162(36.2)$ & $95(37.1)$ & \\
\hline Usual/daily & $91(20.4)$ & $67(34.4)$ & \\
\hline Eating fried food & & & 0.002 \\
\hline None/seldom & $165(37.0)$ & $65(27.0)$ & \\
\hline Regular & $214(47.9)$ & $121(47.3)$ & \\
\hline Usual/daily & $63(15.2)$ & $57(25.8)$ & \\
\hline Eating drink with sugar & & & 0.012 \\
\hline None/seldom & $101(22.6)$ & $52(20.4)$ & \\
\hline Regular & $159(35.5)$ & $70(27.5)$ & \\
\hline Usual/daily & $143(41.9)$ & $97(52.1)$ & \\
\hline Daily drink over $1500 \mathrm{~mL}$ water & & & 0.173 \\
\hline None/seldom & $135(30.0)$ & $83(37.0)$ & \\
\hline Regular & $154(34.2)$ & 89 (34.6) & \\
\hline Usual/daily & $113(35.8)$ & $50(25.4)$ & \\
\hline Eating fast food & & & 0.007 \\
\hline None/seldom & $242(53.9)$ & $99(41.8)$ & \\
\hline Regular & $170(37.9)$ & $113(44.5)$ & \\
\hline Usual/daily & $37(8.2)$ & $31(13.8)$ & \\
\hline Junk food used as regular food & & & $<0.001$ \\
\hline None/seldom & $262(58.6)$ & $90(41.7)$ & \\
\hline Regular & $145(32.4)$ & $107(42.5)$ & \\
\hline Usual/daily & $39(8.7)$ & 34 (15.9) & \\
\hline
\end{tabular}


eating breakfast, were not significantly correlated with chronic constipation. However, unhealthy behaviors, such as eating snacks, fried food and junk food in place of regular food, were significantly correlated with chronic constipation.

Using multivariate logistic regression adjusted for age, sex, race and BMI, we found some lifestyle factors significantly correlated with chronic constipation in university students (Table 2). For healthy behaviors, regular physical activity and daily water intake of over $1500 \mathrm{~mL}$ significant decreased the risk of chronic constipation. If all university students were to adapt these two healthy behaviors, we could reduce chronic constipation by forty percent. However, unhealthy lifestyles were related to a high risk of chronic constipation, including the regular consumption of fried food, fast food or junk food as regular food, doubled the risk of chronic constipation.

In Table 3, we found some lifestyle factors significantly correlated with ratings of self-rated health. Using multivariate logistic regression adjusted for age, sex, race and BMI, we discovered that university students with healthy behaviors had significant higher self-rated health status. University students engaging in regular physical activity (OR $=6.1, p<0.001)$ and drinking over $1500 \mathrm{~mL}$ water per day $(\mathrm{OR}=3.9, p<0.001)$ showed greater well-being in their self-rated health status. Although unhealthy behaviors in university students were not significantly correlated with self-rated health ratings, the ORs of self-rated good health status were found to be under one, implying poor self-rated health status. While university students often eat late-night snacks, only about half of our university students showed poor self-rated health status ( $\mathrm{OR}=0.53, p=0.054)$. Similarly, the regular eating of fried food $(\mathrm{OR}=0.66, p=0.211)$ or junk food $(\mathrm{OR}=0.68, p=0.334)$ as regular food induced poorer self-rated health status.

Table 2. Factors of life styles affecting having constipation using multivariate logistic regression adjusted for age, sex, race and BMI $(\mathrm{N}=810)$.

\begin{tabular}{|c|c|c|}
\hline & OR $(95 \% \mathrm{CI})$ & $p$ \\
\hline \multicolumn{3}{|l|}{ Eating fried food } \\
\hline None/seldom & 1.0 & - \\
\hline Regular & $1.50(0.99-2.27)$ & 0.053 \\
\hline Usual/daily & $1.93(1.15-3.21)$ & 0.012 \\
\hline \multicolumn{3}{|l|}{ Eating fast food } \\
\hline None/seldom & 1.0 & - \\
\hline Regular & $1.59(1.09-2.32)$ & 0.015 \\
\hline Usual/daily & $2.08(1.13-3.85)$ & 0.020 \\
\hline \multicolumn{3}{|c|}{ Use junk food as regular food } \\
\hline None/seldom & 1.0 & - \\
\hline Regular & $1.77(1.23-2.60)$ & 0.004 \\
\hline Usual/daily & $2.60(1.46-4.65)$ & 0.001 \\
\hline \multicolumn{3}{|c|}{ Regular physical activity } \\
\hline None/seldom & 1.0 & - \\
\hline Regular & $0.60(0.40-0.90)$ & 0.013 \\
\hline Usual/daily & $0.63(0.38-1.01)$ & 0.071 \\
\hline \multicolumn{3}{|c|}{ Daily drink over $1500 \mathrm{ml}$ water } \\
\hline None/seldom & 1.0 & - \\
\hline Regular & $0.89(0.59-1.36)$ & 0.599 \\
\hline Usual/daily & $0.59(0.38-0.92)$ & 0.020 \\
\hline
\end{tabular}


Table 3. Factors of lifestyles affecting self-rated good health status using multivariate logistic regression adjusted for age, sex, race and BMI $(\mathrm{N}=810)$.

\begin{tabular}{|c|c|c|}
\hline & OR (95\%CI) & $p$ \\
\hline \multicolumn{3}{|l|}{ Eating fried food } \\
\hline None/seldom & 1.0 & - \\
\hline Regular & $0.65(0.40-1.06)$ & 0.084 \\
\hline Usual/daily & $0.66(0.35-1.26)$ & 0.211 \\
\hline \multicolumn{3}{|l|}{ Eating fast food } \\
\hline None/seldom & 1.0 & - \\
\hline Regular & $0.96(0.60-1.54)$ & 0.869 \\
\hline Usual/daily & $1.06(0.49-2.28)$ & 0.882 \\
\hline \multicolumn{3}{|c|}{ Use junk food as regular food } \\
\hline None/seldom & 1.0 & - \\
\hline Regular & $0.70(0.43-1.15)$ & 0.158 \\
\hline Usual/daily & $0.68(0.31-1.49)$ & 0.334 \\
\hline \multicolumn{3}{|c|}{ Regular physical activity } \\
\hline None/seldom & 1.0 & - \\
\hline Regular & $3.10(1.54-6.23)$ & 0.002 \\
\hline Usual/daily & $6.06(2.93-12.55)$ & $<0.001$ \\
\hline \multicolumn{3}{|c|}{ Daily drink over $1500 \mathrm{ml}$ water } \\
\hline None/seldom & 1.0 & - \\
\hline Regular & $2.57(1.32-4.98)$ & 0.005 \\
\hline Usual/daily & $3.92(2.05-7.49)$ & $<0.001$ \\
\hline \multicolumn{3}{|c|}{ Eating drink with sugar } \\
\hline None/seldom & 1.0 & - \\
\hline Regular & $0.69(0.38-1.26)$ & 0.231 \\
\hline Usual/daily & $0.81(0.47-1.40)$ & 0.444 \\
\hline \multicolumn{3}{|c|}{ Eating late-night snack } \\
\hline None/seldom & 1.0 & - \\
\hline Regular & $0.55(0.33-0.93)$ & 0.024 \\
\hline Usual/daily & $0.53(0.28-1.01)$ & 0.054 \\
\hline \multicolumn{3}{|c|}{ Regular eating breakfast } \\
\hline None/seldom & 1.0 & - \\
\hline Regular & $1.38(0.63-3.02)$ & 0.415 \\
\hline Usual/daily & $1.24(0.65-2.36)$ & 0.517 \\
\hline
\end{tabular}

\section{Discussion}

The prevalence of constipation in the worldwide general population ranges from $0.7 \%$ to $79 \%$ (median $16 \%$ ) 
and is highly dependent on myriad factors. Among them, gender, age, socioeconomic status and educational level meaningfully affect constipation prevalence [5] [12]. In our study, the 36\% of chronic constipation in college students was higher than the percentages of other studies, such as $30.8 \%$ for 52 university students in Brazil and $14 \%$ in the Asian population [13] [14]. Except for individual genetic variability, different findings on chronic constipation can be attributable to methodological methods and differences in lifestyles. The typical medical definition of constipation includes infrequent or difficult evacuation of feces, and physicians often define constipation as a bowel movement every 3 to 4 days or fewer [15].

A more detailed diagnosis of chronic constipation is given by the Rome II criteria. The criteria are as follows: In the preceding 12 months, a patient has had two or more of the following conditions: less than three bowl movements per week, straining at stool more than $25 \%$ of the time, passage of lumpy or hard stools more than $25 \%$ of the time, sensation of incomplete evacuation for more than $25 \%$ of the time, sensation of anorectal obstruction/blockage for more than $25 \%$ of the time and manual maneuvers to facilitate more than $25 \%$ of the time of defecation. Generally speaking, the Rome II criteria were used to assist diagnosis of functional constipation [16].

However, the Rome II criteria might not be suitable if the patient is taking laxatives and does not assess the severity of constipation. 85\% of physician visits for constipation in the US result in a prescription for laxatives or cathartics [17]. Moreover, The Rome II (and more recently the Rome III) criteria were an attempt to formalize the assessment of constipation but resulted in being complex to the point that few practitioners use them in practice.

In this study, our Chinese questionnaire diagnosed constipated subjects easily and accurately assessed their symptom frequency and severity with a sensitivity of $91 \%$ and a specificity of $91 \%$ [11]. Our questionnaire was, in fact, a combination of the Rome II criteria and the PAC-SYM. The latter played a role in assessing both the frequency of constipation symptoms (i.e., <3 bowel movements per week) and the use of laxatives [18].

The most common causes of constipation in primary care are related to diet, fluid intake and psychological factors. There might be several-possibly simultaneous-causes for constipation, including inadequate fiber and fluid intake, sedentary lifestyle and environmental changes. Because most constipated people have unhealthy lifestyles and a poor intake of dietary fiber, a lack of fluids, too little exercise, an absence of routine and high levels of stress, their digestive systems can be easily disrupted. Moreover, the severity or symptoms of constipation might be aggravated by travel, pregnancy or changes in diet. Because the majority of university students are negligible of health-promoting behaviors and reveal behavioral health risks, researchers should assess the relationship between students' unhealthy lifestyles and the risk factors for constipation. In this study, university students with a significantly decreased risk of chronic constipation reported healthy behaviors, such as regular physical activity and water intake over $1500 \mathrm{~mL}$. In contrast, a high risk of chronic constipation was found in students with unhealthy lifestyles, such as the regular consumption of fried food, fast food or junk food as regular food. Our findings are consistent with the findings from the Nurses' Health Study, showing a lower prevalence of constipation in women whose reports placed them in the highest quintile of dietary fiber intake (median intake $20 \mathrm{~g} /$ day $)(\mathrm{PR}=0.64,95 \% \mathrm{CI}=0.57-0.73)$ and in those in this group who also reported daily physical activity-0.32 (95\% CI $=0.20-0.54)$ [19]. We conclude that students who frequently consume of junk food or fast food will have a significantly higher risk of constipation.

Our findings on the effects of diet on chronic constipation are well-founded. In a study drawing from a population similar to ours, researchers investigated the diets of 3,835 female Japanese students. They found a higher risk of constipation in the group with the highest quintile of dietary intake, when comparing the group to the lowest-1.64 (OR = $1.30-2.08 ; p<0.001)$ for confectioneries and $1.41(1.11-1.78 ; p<0.01)$ for bread [20]. A similar nationwide survey was conducted for Taiwanese elementary school students in 2011. The results showed that the risk of constipation was significantly correlated with a lower intake of vegetables, fruits, soybean products, and eggs.

These results make sense. Constipation is caused by stools spending too much time in the colon, absorbing too much water, making them hard and dry. Thus fiber helps stools stay soft so that they move smoothly through the colon. Liquids such as water and juice also improve the effectiveness of fiber. However, contradictive evidence shows that neither total dietary fiber intake nor other lifestyle factors are associated with constipation. This was true, for instance, in one study of Japanese women aged 18 - 20 years [21]. A US study with seniors, ages 65 to 93, showed that self-reported constipation was positively correlated with the amount of liquids consumed in men, but that it was not related to fiber and liquids across sex [22]. Neither low intakes of dietary fiber, 
fruit, vegetables, bread and cereals, nor fluid were associated with an increased occurrence of constipation among seniors, 70 years and over, in New Zealand [23].

Delay in transit within the colon is the most frequent non-obstructive cause of constipation. Colonic transit times are significantly delayed with aging. Moreover, constipated elderly frequently use laxatives and commercial fiber additions (e.g., psyllium; Metamucil) to increase the fiber in their diets. More than 700 commercially available products are touted to relieve the symptoms of constipation. These formulations are not without side effects, of which some are quite significant [24]. However, a diet rich in fiber still plays a critical role in bowel function, especially in the elderly. Sufficient evidence shows fiber acting to increase stool bulk and weight and to hasten intestinal transit time [25]. Greater amounts of crude dietary fiber are associated with a lower prevalence of constipation and other gastrointestinal disorders, including diverticular disease and colorectal cancer [26].

Our study was not without limitations. We assessed neither the quantity of fruit/vegetables nor the frequency of intake. For obvious reasons, the daily consumption of fruit/vegetables is difficult to both collect and measure- a fact precluding their inclusion in our study. Regardless, we found a high correlation between constipation and self-rated health status through our questionnaire. Some of our findings could prove important in improving the health of students. We found unhealthy behaviors to be dose-dependent, with the worst unhealthy behaviors related to a higher likelihood of constipation and poorer self-rated health status. Because our study showed constipated students to be more likely to engage in unhealthy behaviors, the promotion of healthy lifestyles could feasibly reduce constipation among students. One of the best ways to improve general health in adolescents is through educational courses from school or/and supervised with family members. Therefore, we must understand and evaluate health-promoting behaviors among adolescents to assist them in growing up healthy [27].

\section{Conclusion}

We found chronic constipation to be dose-dependent and negatively correlated with the consumption frequencies of snacks, fast food, and fried food. In addition, chronic constipation positively correlated with the daily consumption of water, physical activity and whether junk food replaced regular food for meals. To create healthy behaviors and reduce the risk for chronic constipation is also to upgrade self-rated health status in university students. Both are urgent, crucial issues in adolescent health.

\section{Acknowledgements}

We would like to thank the Miaoli County Government. We would also like to thank all participants who gave their time to make this project a reality.

\section{References}

[1] Loening-Baucke, V. (1995) Functional Constipation. Seminars, in Pediatric Surgery, 4, 26-34.

[2] Wu, T.C., Chen, L.K., Pan, W.H., Tang, R.B., Hwang, S.J., Wu, L., Eugene J.F. and Chen, P.H. (2011) Constipation in Taiwan Elementary School Students: A Nationwide Survey. Journal of Chinese Medical Association, 74, 57-61. http://dx.doi.org/10.1016/j.jcma.2011.01.012

[3] Ip, K.S., Lee, W.T., Chan, J.S. and Young, B.W. (2005) A Community-Based Study of the Prevalence of Constipation in Young Children and the Role of Dietary Fibre. Hong Kong Medical Journal, 11, 431-436.

[4] Mugie, S.M., Benninga, M.A. and Di Lorenzo, C. (2011) Epidemiology of Constipation in Children and Adults: A Systematic Review. Best Practice \& Research. Clinical Gastroenterology, 25, 3-18. http://dx.doi.org/10.1016/j.bpg.2010.12.010

[5] Morais, M.B., Vítolo, M.R., Aguirre, A.N. and Fagundes-Neto, U. (1999) Measurement of Low Dietary Fiber Intake as a Risk Factor for Chronic Constipation in Children. Journal of Pediatric Gastroenterology and Nutrition, 29, $132-135$. http://dx.doi.org/10.1097/00005176-199908000-00007

[6] Inan, M., Aydiner, C.Y., Tokuc, B., Aksu, B., Ayvaz, S., Ayhan, S., Ceylan, T. and Basaran, U.N. (2007) Factors Associated with Childhood Constipation. Journal of Paediatrics and Child Health, 43, 700-706. http://dx.doi.org/10.1111/j.1440-1754.2007.01165.x

[7] Irwin, J.D. (2007) The Prevalence of Physical Activity Maintenance in a Sample of University Students: A Longitudinal Study. Journal of American College Health, 56, 37-41. http://dx.doi.org/10.3200/JACH.56.1.37-42

[8] Lee, R.L. and Loke, A.J. (2005) Health-Promoting Behaviors and Psychosocial Well-Being of University Students in 
Hong Kong. Public Health Nursing, 22, 209-220. http://dx.doi.org/10.1111/j.0737-1209.2005.220304.x

[9] Pullman, A.W., Masters, R.C., Zalot, L.C., Carde, L.E., Saraiva, M.M., Dam, Y.Y., Randall Simpson, J.A. and Duncan, A.M (2009) Effect of the Transition from High School to University on Anthropometric and Lifestyle Variables in Males. Applied Physiology, Nutrition, and Metabolism, 34, 162-171. http://dx.doi.org/10.1139/H09-007

[10] Li, S.F., Lu, J.H. and Wang, H.H. (2009) Exploring the Relationships of Physical Activity, Emotional Intelligence and Health in Taiwan College Students. Journal of Exercise Science and Fitness, 7, 55-63. http://dx.doi.org/10.1016/S1728-869X(09)60008-3

[11] Chan, A.O., Lam, K.F., Hui, W.M., Hu, W.H., Li, J., Lai, K.C., Chan, C.K., Yuen, M.F., Lam, S.K. and Wong, B.C. (2005) Validated Questionnaire on Diagnosis and Symptom Severity for Functional Constipation in the Chinese Population. Alimentary Pharmacology \& Therapeutics, 22, 483-488. http://dx.doi.org/10.1111/j.1365-2036.2005.02621.x

[12] Mugie, S.M., Lorenzo, C.D. and Benninga, M.A. (2011) Constipation in Childhood. Nature Reviews Gastroenterology and Hepatology, 8, 502-511.

[13] Chaud, D., Olivon, E., Machado, A. and Abreu, E. (2014) Prevalence of Functional Constipation and Its Risk Factors among University Students. The FASEB Journal, 28, LB328.

[14] Cheng, C., Chan, A.O., Hui, W.M. and Lam, S.K. (2003) Coping Strategies, Illness Perception, Anxiety, and Depression of Patients with Idiopathic Constipation: A Population-Based Study. Alimentary Pharmacology \& Therapeutics, 18, 319-326. http://dx.doi.org/10.1046/j.1365-2036.2003.01663.x

[15] Herz, M.J., Kahan, E., Zalevski, S., Aframian, R., Kuznitz, D. and Reichman, S. (1996) Constipation: A Different Entity for Patients and Doctors. Family Practice, 13, 156-159. http://dx.doi.org/10.1093/fampra/13.2.156

[16] Thompson, W.G., Longstreth, G.F., Drossman, D.A., Heaton, K.W., Irvine, E.J. and Müller-Lissner, S.A. (1999) Functional Bowel Disorders and Functional Abdominal Pain. Gut, 45, II43-II47. http://dx.doi.org/10.1136/gut.45.2008.ii43

[17] Sonnenberg, A. and Koch, T.R. (1989) Physician Visits in the United States for Constipation: 1958-1986. Digestive Diseases and Sciences, 34, 606-611. http://dx.doi.org/10.1007/BF01536339

[18] Frank, L., Kleinman, L., Farup, C., Taylor, L. and Miner Jr., P. (1999) Psychometric Validation of a Constipation Symptom Assessment Questionnaire. Scandinavian Journal of Gastroenterology, 34, 870-877. http://dx.doi.org/10.1080/003655299750025327

[19] Dukas, L., Willett, W.C. and Giovannucci, E.L. (2003) Association between Physical Activity, Fiber Intake, and Other Lifestyle Variables and Constipation in a Study of Women. The American Journal of Gastroenterology, 98, 1790-1796. http://dx.doi.org/10.1111/j.1572-0241.2003.07591.X

[20] Murakami, K., Sasakii, S., Okubo, H., Takahashi, Y., Hoso, Y. and Itabashi, M., Freshmen in Dietetic Courses Study II Group (2007) Food Intake and Functional Constipation: A Cross-Sectional Study of 3,835 Japanese Women Aged 18-20 Years. Journal of Nutritional Science and Vitaminology (Tokyo), 53, 30-36. http://dx.doi.org/10.3177/jnsv.53.30

[21] Murakami, K., Okubo, H. and Sasaki, S. (2006) Dietary Intake in Relation to Self-Reported Constipation among Japanese Women Aged 18 - 20 Years. European Journal of Clinical Nutrition, 60, 650-657. http://dx.doi.org/10.1038/sj.ejcn.1602365

[22] Whitehead, W.E., Drinkwater, D., Cheskin, L.J., Heller, B.R. and Schuster, M.M. (1989) Constipation in the Elderly Living at Home. Definition, Prevalence, and Relationship to Lifestyle and Health Status. Journal of the American Geriatrics Society, 37, 423-429.

[23] Campbell, A.J., Busby, W.J. and Horwath, C.C. (1993) Factors Associated with Constipation in a Community Based Sample of People Aged 70 Years and Over. Journal of Epidemiology \& Community Health, 47, 23-26. http://dx.doi.org/10.1136/jech.47.1.23

[24] Tramonte, S.M., Brand, M.B., Mulrow, C.D., Amato, M.G., O’Keefe, M.E. and Ramirez, G. (1997) The Treatment of Chronic Constipation in Adults: A Systematic Review. Journal of General Internal Medicine, 12, 15-24. http://dx.doi.org/10.1007/s11606-006-0003-5

[25] Andersson, H., Bosaeus, I., Falkheden, T. and Melkersson, M. (1979) Transit Time in Constipated Geriatric Patients during Treatment with a Bulk Laxative and Bran: A Comparison. Scandinavian Journal of Gastroenterology, 14, 821-826. http://dx.doi.org/10.3109/00365527909181410

[26] Painter, N.S. and Burkitt, D.P. (1971) Diverticular Disease of the Colon: A Deficiency Disease of Western Civilization. British Medical Journal, 2, 450-454. http://dx.doi.org/10.1136/bmj.2.5759.450

[27] Wang, D., Ou, C.Q., Chen, M.Y. and Duan, N. (2009) Health-Promoting Lifestyles of University Students in Mainland China. BMC Public Health, 9, 379. http://dx.doi.org/10.1186/1471-2458-9-379 